\title{
ORIGINAL ARTICLE A comparative study of two protocols for treadmill walking exercise testing in ambulating subjects with incomplete spinal cord injury
}

\author{
E Lundgaard, MF Wouda and V Strøm
}

Study Design: This is a comparative study of two exercise testing protocols.

Objectives: The objective of this study was to compare maximal oxygen uptake $\left(\mathrm{VO}_{2}\right.$ max) and achieved criteria for maximal exercise testing between the Sunnaas Protocol—a newly designed treadmill exercise test protocol—and the Modified Bruce Protocol in persons with incomplete spinal cord injury (SCl).

Setting: This study was conducted in Sunnaas Rehabilitation Hospital, Norway.

Methods: Twenty persons (19 men) with incomplete SCI (AIS D) capable of ambulating without assistive devices performed two treadmill walking exercise tests (Sunnaas Protocol and Modified Bruce Protocol) until exhaustion 1-3 days apart. The key differences between the protocols are the smaller increments in speed and shorter duration on each workload in the Sunnaas Protocol. Cardiovascular responses were measured continuously throughout both tests.

Results: The subjects exhibited statistically significantly higher $\mathrm{VO}_{2}$ max when using the Sunnaas Protocol (37.1 \pm 9.9 vs $35.4 \pm 9.8 \mathrm{ml} \mathrm{kg}^{-1} \mathrm{~min}^{-1}, \quad P=0.01$ ), with a mean between-test difference of $1.8 \mathrm{ml} \mathrm{kg}^{-1} \mathrm{~min}^{-1}$ (95\% confidence interval: 0.49-3.16). There was no significant difference in mean maximal heart rate (HR max). Nineteen (95\%) subjects achieved at least three of the four criteria for maximal oxygen uptake using the Sunnaas Protocol. Thirteen (65\%) subjects achieved at least three of the criteria using a Modified Bruce protocol.

Conclusions: The small differences in both $\mathrm{VO}_{2}$ max and achieved criteria in favor of the Sunnaas Protocol suggest that it could be a useful alternative treadmill exercise test protocol for ambulating persons with incomplete SCl.

Spinal Cord (2017) 55, 935-939; doi:10.1038/sc.2017.34; published online 23 May 2017

\section{INTRODUCTION}

Maximal exercise testing provides important information about a person's physical capacity, and it is a useful tool for designing cardiovascular exercise prescriptions. A treadmill exercise test normally yields a higher maximal oxygen uptake $\left(\mathrm{VO}_{2} \max \right)$ compared with an ergometer cycle test in healthy subjects. ${ }^{1,2}$ Most treadmill exercise test protocols are designed to test athletes and persons with normal gait function. These protocols often start with a high speed, and the increments between each stage are often large, as for the Modified Bruce protocol ${ }^{3}$ established for testing elderly and sedentary patients. Such protocols may force persons with gait limitations, as for many people with incomplete SCI, to terminate the exercise test before reaching a maximal effort, and thus before reaching a $\mathrm{VO}_{2}$ max, because of too high treadmill speed. We therefore designed a new treadmill exercise test protocol (the Sunnaas protocol), which involves small increments in workload and with duration of one minute per stage.

When performing treadmill walking, persons with SCI have shown great variability and low maximal walking speed. ${ }^{4-6}$ In the Modified Bruce protocol, the treadmill speed of $4,5.4 \mathrm{~km} \mathrm{~h}^{-1}$ and higher, is greater than what has been reported as maximal walking speed in persons with SCI. ${ }^{4-6}$ Therefore, the Sunnaas Protocol was designed with an initial speed of $3 \mathrm{~km} \mathrm{~h}^{-1}$, which was considered manageable for the target population. In addition, walking on a steep incline $\left(>10^{\circ}\right)$ can be demanding for some subjects with incomplete SCI. ${ }^{7}$ In a study of healthy subjects, ${ }^{8}$ at a grade of 20 and $22 \%$, subjects experienced lumbar and calf discomfort, which was considered a limitation during exercise testing. In our study, the maximal incline was therefore set to $15 \%$ in both protocols to avoid these problems.

There is limited research regarding exercise testing during treadmill walking with full body weight bearing for persons with incomplete SCI. This kind of testing requires a high functional level, which is seen in a small part of the SCI population. In a study by Sorensen, only eight $(3.4 \%)$ out of 236 subjects were capable of ambulating without assistive devices. ${ }^{9}$ To our knowledge, no treadmill exercise test protocol for ambulatory individuals with SCI is established.

Several criteria have to be examined in order to determine whether $\mathrm{VO}_{2}$ max has been reached. ${ }^{10}$ A plateau in $\mathrm{VO}_{2}$, despite an increase in workload, at maximal effort is considered the most reliable criteria for reaching $\mathrm{VO}_{2}$ max. ${ }^{10}$ However, a plateau is often not found in subjects being tested for their maximal oxygen uptake. Therefore, a set of secondary criteria are used to evaluate achievement of $\mathrm{VO}_{2}$ max. ${ }^{11,12}$ The most widely used secondary criteria for healthy subjects are respiratory exchange ratio (RER), a percentage of age-adjusted 
predicted maximal heart rate (HR max) and postexercise blood lactate concentration $\left[\mathrm{La}^{-}\right] .{ }^{10}$ Other studies investigating maximal oxygen uptake in subjects with SCI during arm cranking have used the same physiological variables/measurements to evaluate achievement of $\mathrm{VO}_{2}$ max. ${ }^{6,13}$

The objective of this study was to compare $\mathrm{VO}_{2}$ max and achieved criteria for maximal exercise testing between the Sunnaas Protocol and the Modified Bruce Protocol in ambulating persons with incomplete SCI. We hypothesized that a protocol with relatively small increments in speed and short duration on each workload would yield higher $\mathrm{VO}_{2}$ max values for this group, compared with the Modified Bruce protocol with large increments in speed.

\section{MATERIALS AND METHODS}

\section{Subjects}

Nineteen men and one woman with chronic incomplete SCI (AIS D) were recruited from inpatients at Sunnaas Rehabilitation Hospital (for characteristics, see Table 1). Subjects to be included were eligible if they had an SCI classified as AIS C or D according the standard neurological classification of spinal cord injury defined by the American Spinal Injury Association. ${ }^{14}$ The age at inclusion was set to be between 18 and 65 years. The subjects had to be able to walk for $10 \mathrm{~min}$ on the treadmill at a speed of $3 \mathrm{~km} \mathrm{~h}^{-1}$ without handrail support or use of assistive devices. Subjects were excluded if they had a cardiovascular disease.

\section{Procedures}

All subjects completed two treadmill exercise tests until exhaustion: one using the Sunnaas Protocol (Table 2) and one using a Modified Bruce protocol (Table 3). The exercise tests were performed at the same time of the day on two separate days. The second test was conducted between 1 and 3 days apart. The sequence order was ensured through randomization by drawing lots. For practical reasons, blinding of staff was not possible. The subjects were not told the names of the protocols. The subjects fasted for at least two hours before testing. Throughout the tests, they were not allowed to use any assistive devices or to grip/rest their arms on the handrail. The tests were terminated when the subjects were unable to continue because of exhaustion, or if systolic blood pressure exceeded $250 \mathrm{~mm} \mathrm{Hg}$ or decreased more than 10\% of the resting systolic blood pressure. Subjects were instructed to exercise to their maximal intensity, with vigorous verbal encouragement.

Before testing, all subjects were medically screened by a physician. The treadmill exercise tests were performed at the Clinical Physiological laboratory at Sunnaas Rehabilitation Hospital, Norway. All tests were conducted by the same personnel. No incidents of adverse events were reported during the tests.

Table 1 Characteristics of the subjects $(n=20)$

\begin{tabular}{lcc}
\hline & Mean (s.d.) & Median (range) \\
\hline Age (years) & $46(14)$ & $47(18-65)$ \\
Weight (kg) & $82(13)$ & \\
Height (cm) & $177(8)$ & \\
Smoking, $n$ (\%) & $4(20)$ & $3.9(0.1-16.9)$ \\
Time since injury (years) & $4.5(4.6)$ & \\
Traumatic SCl, $n$ (\%) & $14(70)$ &
\end{tabular}

\begin{tabular}{|c|c|}
\hline Neurological leve ${ }^{A}$ & $\mathrm{n}(\%)$ \\
\hline Cervical 1-8 & $14(70)$ \\
\hline Thoracic 1-5 & $1(5)$ \\
\hline Thoracic 6-12 & $2(10)$ \\
\hline Lumbar 1-5 & $3(15)$ \\
\hline
\end{tabular}

\section{Measurements}

Gas exchange. Oxygen uptake $\left(\mathrm{VO}_{2} ; 1 \mathrm{~min}^{-1}\right)$, carbon dioxide production $\left(\mathrm{VCO}_{2} ; 1 \mathrm{~min}^{-1}\right)$ and ventilation $\left(\mathrm{Ve} ; 1 \mathrm{~min}^{-1}\right)$ were measured continuously throughout both tests using a computerized standard open-circuit technique breath-by-breath spirometer $\left(\mathrm{V}_{\max }\right.$ Encore 229D, CareFusion Corporation, San Diego, CA, USA). The equipment was calibrated before each test. A 3-1 calibration syringe was used for volume calibration. Medically certified calibration gases $\left(16 \% \mathrm{O}_{2} / 4 \% \mathrm{CO}_{2}\right.$ and $\left.26 \% \mathrm{O}_{2} / 0 \% \mathrm{CO}_{2}\right)$ and room air were used for calibrating the gas analyzers. To evaluate the subjects' functional capacity, oxygen uptake in $\mathrm{ml} \mathrm{kg}^{-1} \mathrm{~min}^{-1}$ was calculated.

Heart rate. Heart rate (HR; beats per min) was recorded with a HR monitor (Polar Sport tester, Polar Electro Inc., Kempele, Finland). The highest achieved heart rate was considered HR max.

Blood pressure. Blood pressure $(\mathrm{BP} ; \mathrm{mm} \mathrm{Hg})$ was measured at rest before testing, each third minute during testing and at cessation of the test, using an automatic blood pressure device (Tango 2, SunTech Medical Instruments Inc., Morrisville, NC, USA).

Blood lactate. Blood lactate concentration ( $\left.\left[\mathrm{La}^{-}\right] ; \mathrm{mmol} \mathrm{l}^{-1}\right)$ was measured $2 \mathrm{~min}$ into recovery. Blood $(20 \mu \mathrm{l})$ was taken from the fingertip, mixed with a standard lactate hemolyzing solution and analyzed with a Biosen C-line Lactate analyzer (Biosen C-line, Sport, EKF Diagnostics, Barleben, Germany). The

\section{Table 2 The Sunnaas protocol}

\begin{tabular}{|c|c|c|c|}
\hline Stage (time total) & Speed $\left(k m h^{-1}\right)$ & Incline (\%) & Duration (min) \\
\hline 1 & 3 & 1 & 1 \\
\hline 2 & 3 & 3 & 1 \\
\hline 3 & 3 & 5 & 1 \\
\hline 4 & 3 & 7 & 1 \\
\hline 5 & 3 & 9 & 1 \\
\hline 6 & 3 & 11 & 1 \\
\hline 7 & 3 & 13 & 1 \\
\hline 8 & 3 & 15 & 1 \\
\hline 9 & 3.5 & 15 & 1 \\
\hline 10 & 4 & 15 & 1 \\
\hline 11 & 4.5 & 15 & 1 \\
\hline 12 & 5 & 15 & 1 \\
\hline 13 & 5.5 & 15 & 1 \\
\hline 14 & 6 & 15 & 1 \\
\hline 15 & 6.5 & 15 & 1 \\
\hline 16 & 7 & 15 & 1 \\
\hline 17 & 7.5 & 15 & 1 \\
\hline 18 & 8 & 15 & 1 \\
\hline 19 & 8.5 & 15 & 1 \\
\hline 20 & 9 & 15 & 1 \\
\hline 21 & 9.5 & 15 & 1 \\
\hline
\end{tabular}

Table 3 Modified Bruce protocol

\begin{tabular}{lllcc}
\hline Stage & Speed $\left(\mathrm{km} \mathrm{h}^{-1}\right)$ & Incline (\%) & Duration (min) & Duration total (min) \\
\hline 0 & 2.7 & 0 & 3 & 3 \\
0.5 & 2.7 & 5 & 3 & 6 \\
1 & 2.7 & 10 & 3 & 9 \\
2 & 4 & 12 & 3 & 12 \\
3 & 5.4 & 14 & 3 & 15 \\
4 & 6.7 & 15 & 3 & 18 \\
5 & 8 & 15 & 3 & 21 \\
6 & 8.8 & 15 & 3 & 24 \\
7 & 9.6 & 15 & 3 & 27 \\
\hline
\end{tabular}


Table 4 Cardiovascular responses at maximal workloads during the two treadmill exercise test protocols $(n=20)$

\begin{tabular}{|c|c|c|c|c|}
\hline Parameter & Sunnaas mean (s.d.) min-max & Mod. Bruce mean (s.d.) min-max & Between-group difference $(95 \% \mathrm{Cl})$ & P-value \\
\hline Maximal oxygen uptake $\left(\mathrm{VO}_{2} \mathrm{ml} \mathrm{kg}^{-1} \mathrm{~min}^{-1}\right)$ & 37.1 (9.9) 23.7-58.5 & $35.3(9.8) 22.5-57.5$ & $1.8(0.49-3.16)$ & $0.01^{\mathrm{a}}$ \\
\hline Blood lactate $\left(\mathrm{mmol} \mathrm{I}^{-1}\right)$ & $7.83(2.80) 3.54-12.60$ & 7.12 (2.98) $1.87-12.82$ & $0.71(0.04-1.37)$ & $0.039^{a}$ \\
\hline Respiratory exchange ratio & $1.20(0.07) 1.10-1.30$ & $1.16(0.09) 1.01-1.31$ & $0.04(0.00-0.08)$ & $0.047^{a}$ \\
\hline Maximal ventilation $\left(I \mathrm{~min}^{-1}\right)$ & 103 (33) 55-168 & 96 (31) 50-150 & $7(2-13)$ & $0.009^{a}$ \\
\hline
\end{tabular}

Abbreviations: $\mathrm{Cl}$, confidence interval; $\mathrm{PRE}$, rating of perceived extertion; $\mathrm{VO}_{2}$, oxygen uptake.

aThe difference between the protocols is statistically significant at a level $<0.05$.

lactate analyzer was calibrated before each measurement using a standard lactate system solution $\left(12 \mathrm{mmol}^{-1}\right)$. Before exercise, the subject's height (nearest $0.1 \mathrm{~cm}$ ) and weight (nearest $0.5 \mathrm{~kg}$ ) were recorded. The data from the tests $\left(\mathrm{VO}_{2}, \mathrm{RER}\right.$ and $\left.\mathrm{Ve}\right)$ were time-averaged into 30 -s intervals. If no $\mathrm{VO}_{2}$ plateau was achieved, the highest average over $30 \mathrm{~s}$ was considered $\mathrm{VO}_{2}$ max.

The preset criteria for reaching maximal oxygen uptake were set to achievement of a $\mathrm{VO}_{2}$ plateau $\left(\leqslant 2 \mathrm{ml} \mathrm{kg}^{-1} \mathrm{~min}^{-1}\right.$ rise in $\mathrm{VO}_{2}$ despite increased workload at maximal intensity), RER $\geqslant 1.05,\left[\mathrm{La}^{-}\right] \geqslant 5 \mathrm{mmoll}^{-1}$ and $\geqslant 95 \%$ of predicted maximal $\mathrm{HR}$, using the formula 220 -age.

Sample size calculation. Sample size calculation was done a priori based on a minimum clinically important between-test difference in $\mathrm{VO}_{2} \max$ of $3 \mathrm{ml} \mathrm{kg}^{-1} \mathrm{~min}^{-1}$, with an s.d. of $4 \mathrm{ml} \mathrm{kg}^{-1} \mathrm{~min}^{-1}$. With a power of $80 \%$ and a significance level of 0.05 , a sample size of 22 was needed.

Statistics. The results are presented as mean and s.d., between-group difference and 95\% confidence interval (CI), if not otherwise stated. Paired Student's $t$-test was used to test the results for systematic disagreement between the Sunnaas and the Modified Bruce protocols. Bland-Altman plots were constructed to assess the results for agreement between the two protocols across the range of oxygen uptake, and to explore extreme values. The mean differences, s.d. of the difference and 95\% limits of agreement were calculated according to Bland and Altman. ${ }^{15}$ Fisher's exact test was used to test the number of criteria achieved in the two protocols, and odds ratios were calculated to quantify the relationship between the criteria for fulfillment of $\mathrm{VO}_{2}$ max and the studied protocols. A $P$-value $<0.05$ was regarded as statistically significant. All statistical analyses were conducted on SPSS Statistics 19

\section{Statement of ethics}

The study was approved by the Regional Committees for Medical and Health Research Ethics (REC; South East; 2013/159). All subjects signed written informed consent forms before participating in the study. We certify that all applicable institutional and governmental regulations concerning the ethical use of human volunteers were followed during the course of this research. All subjects were informed of the purpose, procedure and potential risks of the study with written and verbal communications before they signed informed consent documents.

\section{RESULTS}

\section{Cardiovascular responses}

$\mathrm{VO}_{2}$ max was statistically significantly higher when using the Sunnaas Protocol compared with the Modified Bruce protocol (Table 4). The between-test difference was $1.8 \mathrm{ml} \mathrm{kg}^{-1} \min ^{-1}$ (95\% CI: $0.49,3.16$ ). Seventeen out of twenty subjects achieved higher $\mathrm{VO}_{2}$ max using the Sunnaas Protocol (Figure 1). The s.d. of the differences in $\mathrm{VO}_{2} \max$ was $2.8 \mathrm{ml} \mathrm{kg}^{-1} \mathrm{~min}^{-1}$. The $95 \%$ ( \pm 2 s.d.) limits of agreement ranged from $7.4 \mathrm{ml} \mathrm{kg}^{-1} \mathrm{~min}^{-1}$ to $-3.8 \mathrm{ml} \mathrm{kg}^{-1} \mathrm{~min}^{-1}$ (Sunnaas minus Mod. Bruce) (Figure 1). Visual inspection of the Bland-Altman

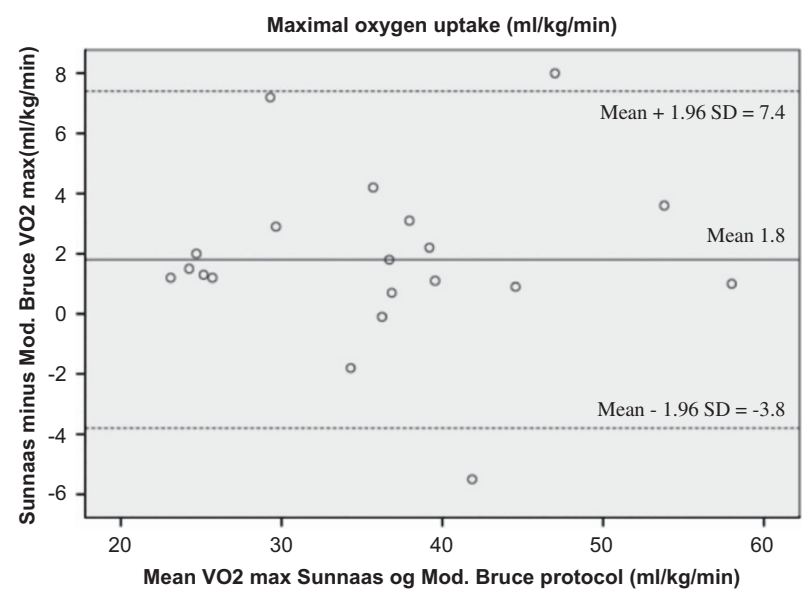

Figure 1 Bland-Altman plots depicting mean differences for maximal oxygen uptake during treadmill walking. The solid line represents the mean, and the dashed line represents the $95 \% \mathrm{Cls}$ (mean \pm 1.96 s.d.) of the observations.

plot revealed small differences in $\mathrm{VO}_{2}$ max between the two protocols at values below $30 \mathrm{ml} \mathrm{kg}^{-1} \mathrm{~min}^{-1}$, and larger variance at levels above $30 \mathrm{ml} \mathrm{kg}^{-1} \mathrm{~min}^{-1}$.

RER and lactate were statistically significantly higher when using the Sunnaas Protocol compared with the Modified Bruce Protocol. There was no statistically significant difference in mean HR max between the two protocols (Table 4).

All subjects had an increase in systolic blood pressure from rest to maximal exercise during both tests (for the Sunnaas Protocol from $131( \pm 15) \mathrm{mm} \mathrm{Hg}$ at rest to $195( \pm 25) \mathrm{mm} \mathrm{Hg}$ at max, and for the Modified Bruce Protocol from $133( \pm 15) \mathrm{mm} \mathrm{Hg}$ to $186( \pm 27)$ $\mathrm{mm} \mathrm{Hg}$ ). The subjective reasons for terminating the exercise test using the Sunnaas Protocol were exhaustion $(50 \%, n=10)$, dyspnea $(15 \%$, $n=3$ ) and difficulty maintaining/increasing treadmill speed according to the test protocol $(15 \%, n=3)$. Leg pain $(10 \%, n=2)$, spasticity $(5 \%, n=1)$ and muscular fatigue $(5 \%, n=1)$ were less common. Using the Modified Bruce Protocol, the reasons for terminating the exercise test were difficulty maintaining/increasing treadmill speed according to the test protocol $(35 \%, n=7)$, exhaustion $(25 \%, n=5)$ and experienced muscular fatigue $(25 \%, n=5)$. Leg pain was experienced by one subject $(5 \%)$ and dyspnea by two subjects $(10 \%)$. The mean minimal treadmill speed (using either Sunnaas or Modified Bruce Protocol) was $5.73 \mathrm{~km} \mathrm{~h}^{-1}( \pm 1.59)$. None of the tests were interrupted because of high blood pressure or symptoms of dizziness or chest pain. Two subjects performed only one test because of sickness. Their results were excluded in the statistical analysis. 
Table 5 Number of subjects achieving established criteria for $\mathrm{VO}_{2}$ max during the two treadmill exercise test protocols $(n=20)$

\begin{tabular}{lccc}
\hline Criteria & Sunnaas n (\%) & Mod. Bruce $\mathrm{n}(\%)$ & Odds ratio (95\% Cl) \\
\hline VO $_{2}$ plateau: $<2 \mathrm{ml} \mathrm{kg}^{-1} \mathrm{~min}^{-1}$ increase & $19(95 \%)$ & $15(75 \%)$ & $6.33(0.67-60.16)$ \\
Maximal heart rate: $\geqslant 95 \%$ of 220 -age & $16(80 \%)$ & $14(70 \%)$ & $1.71(0.4-7.34)$ \\
Maximal blood lactate: $\geqslant 5 \mathrm{mmol} \mathrm{I}^{-1}$ & $15(75 \%)$ & $14(70 \%)$ & $17(85 \%)$ \\
Respiratory exchange ratio: $\geqslant 1.05$ & $20(100 \%)$ & $13(65 \%)$ & $\mathrm{c}-5.18)$ \\
Fulfilling $\geqslant 3$ of the criteria above & $19(95 \%)^{\mathrm{b}}$ & & $10.23(1.12-93.34)$
\end{tabular}

Abbreviations: $\mathrm{Cl}$, confidence interval; $\mathrm{VO}_{2}$, oxygen uptake.

aFor each subject, each criterion was coded as 'yes' and 'no', depending on the fulfillment of a criterion or not. Then all the 'yes' was summarized.

${ }^{b} T h e$ difference between the protocols is statistically significant at a level $<0.05$ (Fisher's exact test)

'One case (not fulfilled RER criterion for the Sunnaas protocol) with value of 0 , odds ratio is undefined.

\section{Achieved criteria for maximal oxygen uptake}

There were no statistically significant differences between the protocols in achievement of the preset criteria, when each criterion was analyzed separately (Table 5). Comparing the number of subjects achieving at least three of the four criteria for maximal oxygen uptake revealed a statistically significant difference $(P=0.04)$ with an odds ratio $(\mathrm{OR})$ of 10.23 (95\% CI: 1.12, 93.34) in favor of the Sunnaas protocol.

\section{DISCUSSION}

This study compared maximal oxygen uptake and achieved criteria during treadmill walking in ambulatory subjects with SCI, using two different test protocols. The main results were the mean between-test difference found in $\mathrm{VO}_{2}$ max of $1.8 \mathrm{ml} \mathrm{kg}^{-1} \mathrm{~min}^{-1}$ and that more subjects achieved three or more of the $\mathrm{VO}_{2}$ max end criteria, both in favor of the Sunnaas Protocol.

We hypothesized that a protocol with smaller increments in speed and shorter duration on each workload, as the Sunnaas Protocol, would yield higher $\mathrm{VO}_{2}$ max values for this group, as suggested by Buchfuhrer et al., ${ }^{16}$ compared with the Modified Bruce Protocol. The difference found in $\mathrm{VO}_{2}$ max was small but statistically significant $(P=0.01)$. The lower bound of the $95 \%$ CI $\left(0.49 \mathrm{ml} \mathrm{kg}^{-1} \mathrm{~min}^{-1}\right)$ indicates that the real difference might be even smaller than $1.8 \mathrm{ml} \mathrm{kg}^{-1} \mathrm{~min}^{-1}$. The difference is also smaller than what we considered to be clinically significant. However, the upper bound of the $95 \% \mathrm{CI}\left(3.16 \mathrm{ml} \mathrm{kg}^{-1} \mathrm{~min}^{-1}\right)$ indicates a difference that could be regarded as large enough to be considered clinically important. The between-test difference in $\mathrm{VO}_{2} \max$ of $1.8 \mathrm{ml} \mathrm{kg}^{-1} \mathrm{~min}^{-1}$ is within the same range as studies that did not find any statistically significant differences in $\mathrm{VO}_{2}$ max between test protocols. ${ }^{12,17-19}$ In our study, 17 out of 20 subjects exhibited their highest $\mathrm{VO}_{2}$ using the Sunnaas Protocol, which might explain the statistical difference.

The Bland-Altman plot (Figure 1) showed a small within-subject difference in $\mathrm{VO}_{2}$ max between the two protocols in the subjects with the lowest $\mathrm{VO}_{2}$ max values (about $25 \mathrm{ml} \mathrm{kg}^{-1} \mathrm{~min}^{-1}$ ). In general, those subjects terminated the tests because of difficulties maintaining treadmill speed according to the test protocols. The same subjects also achieved the lowest number of end criteria. The within-subject difference for the subjects with $\mathrm{VO}_{2} \max \geqslant 30 \mathrm{ml} \mathrm{kg}^{-1} \mathrm{~min}^{-1}$ is larger. The three extreme values (see Figure 1) seem not to be influenced by the subjects' physical capacity. Whether these extreme values are random or not is difficult to determine because of the small sample size.

All the subjects in the present study had chronic incomplete SCI classified as AIS D. They were able to walk on a treadmill without handrail support or use of assistive devices-however, not without some walking difficulties. The $\mathrm{VO}_{2} \max \left(\mathrm{ml} \mathrm{kg}^{-1} \mathrm{~min}^{-1}\right)$ was quite high, in average $91 \%$ of the reference values for healthy subjects. ${ }^{20}$ In the study by Saraf et al., ${ }^{6}$ the average $\mathrm{VO}_{2}$ max was $22 \mathrm{ml} \mathrm{kg}^{-1} \mathrm{~min}^{-1}$ in the AIS D group, with a higher male: female ratio, 18:7. Whether the Sunnaas Protocol is suitable for subjects with lower physical capacity levels (that is, $\mathrm{VO}_{2} \max \leqslant 20 \mathrm{ml} \mathrm{kg}^{-1} \mathrm{~min}^{-1}$ ) remains to be tested. The mean maximal treadmill walking speed reached in the present study $\left(5.73 \mathrm{~km} \mathrm{~h}^{-1}\right)$ was higher than in other studies investigating maximal walking speed in subjects with incomplete SCI. ${ }^{4,6}$ The subjects in our study could thus be considered high functional persons with SCI, even though the between-subject difference in both maximal oxygen uptake and maximal walking speed during exercise testing was large.

The large speed increments in the Modified Bruce Protocol were demanding for some of the subjects. Seven of the subjects terminated the test during this protocol because of difficulties maintaining/ increasing the treadmill speed, probably before reaching a maximal effort. Three of those subjects terminated the Sunnaas Protocol for the same reason. Although not statistically significant, the median Borg scale was highest using the Sunnaas Protocol. This indicates that more subjects were able to reach a higher level of exhaustion using the Sunnaas Protocol. In addition, the higher number of subjects achieving three or more of the end criteria, as well as the large point estimate of the OR (Table 5), suggest that there was an association between achievement of the $\mathrm{VO}_{2}$ max criteria and the protocol with smaller increments in speed and shorter duration on each workload. However, because of the wide CI of the OR $(1.12,93.34)$, it is necessary to be cautious about the interpretation of this finding.

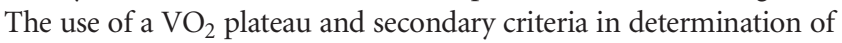
$\mathrm{VO}_{2}$ max is highly debated. A plateau in $\mathrm{VO}_{2}$ at the end of a test is not always a valid measurement of $\mathrm{VO}_{2} \max ^{11,21}$ because of a low plateau incidence and the occurrence of $\mathrm{VO}_{2}$ plateaus at submaximal exercise levels. Some of the plateaus at termination of the test in our study were probably at submaximal exercise level. The blood lactate and RER were significantly higher using the Sunnaas Protocol, although the difference was small. Only small differences were found when comparing the criteria separately, but when combining them, as suggested by others, ${ }^{11}$ it might indicate that the Sunnaas Protocol is better in detecting whether maximal effort is achieved.

Our results revealed no significant difference in the maximal HR between the two protocols. Similar results have been shown in previous studies comparing treadmill exercise test protocols in healthy subjects. ${ }^{12,17,18,22}$ The percentage of expected HR max had a wide range, indicating normal between-subject differences. Maximal HR of at least $95 \%$ of age-predicted heart rate (220-age) is often used as heart rate end criterion, although this criterion is widely debated. ${ }^{10}$ From a clinical point of view, the HR max is one of the most important variables derived from an exercise test. A certain \% of $\mathrm{HR}$ max is widely used in aerobic exercise prescription. The mean difference in HR max between the two protocols was only 2 beats per min ( $95 \%$ CI; $-1,6)$, which makes the protocols comparable when measuring HR max. 


\section{Study limitations}

The number of subjects in this study was relatively small, and too small to divide into subgroups such as age, sex and injury levels. Each test was performed only once by each subject, which leaves the reliability for both test protocols unknown in ambulatory people with incomplete SCI. However, it would probably be too demanding for the subjects to complete four or six maximal exercise tests in order to measure reliability. In some studies, the subjects have performed pretests at submaximal or maximal exercise intensity to familiarize the subjects with the treadmill and the test equipment. ${ }^{18,22,23}$ In our study, the subjects could have benefitted from a pretest, especially to get comfortable with walking on the treadmill at high speed. The maximal incline of the treadmill set to $15 \%$ was possibly too low. A higher maximal incline might have been more suitable for some of the subjects in order to reach a higher level of exhaustion and $\mathrm{VO}_{2}$ max and also reaching more end criteria. Furthermore, the evaluator reading out the maximal cardiovascular values, set by the measurement software, was not blinded with regard to the protocol used, and could thus have introduced a bias.

\section{CONCLUSION}

The small differences in both $\mathrm{VO}_{2}$ max and achieved criteria between the protocols suggest that the Sunnaas Protocol with small increments in speed and short duration on each workload could be a useful alternative treadmill exercise test protocol for ambulating persons with incomplete SCI. Future studies should aim to measure reliability in $\mathrm{VO}_{2}$ max during treadmill exercise testing in subjects with incomplete SCI. Larger sample size to investigate subgroups of the SCI population, based on level of injury and demographic parameters, is needed.

\section{DATA ARCHIVING}

There were no data to deposit.

\section{CONFLICT OF INTEREST}

The authors declare no conflict of interest.

1 Hermansen L, Saltin B. Oxygen uptake during maximal treadmill and bicycle exercise. J Appl Physiol 1969; 26: 31-37.

2 Carter H, Jones AM, Barstow TJ, Burnley M, Williams CA, Doust JH. Oxygen uptake kinetics in treadmill running and cycle ergometry: a comparison. J App/ Physiol 2000; 89: 899-907.
3 Bruce RA, Kusumi F, Hosmer D. Maximal oxygen intake and nomographic assessment of functional aerobic impairment in cardiovascular disease. Am Heart J 1973; 85: 546-562.

4 Pepin A, Norman KE, Barbeau H. Treadmill walking in incomplete spinal-cord-injured subjects: 1. adaptation to changes in speed. Spinal Cord 2003; 41: 257-270.

$5 \mathrm{Kim}$ CM, Eng JJ, Whittaker MW. Level walking and ambulatory capacity in persons with incomplete spinal cord injury: relationship with muscle strength. Spinal Cord 2004; 42: $156-162$.

6 Saraf P, Rafferty MR, Moore JL, Kahn JH, Hendron K, Leech K et al. Daily stepping in individuals with motor incomplete spinal cord injury. Phys Ther 2010; 90: 224-235.

7 Leroux A, Fung J, Barbeau H. Adaptation of the walking pattern to uphill walking in normal and spinal-cord injured subjects. Exp Brain Res 1999; 126: 359-368.

8 McArdle WD, Katch FI, Pechar GS. Comparison of continuous and discontinuous treadmill and bicycle tests for max Vo. Med Sci Sports 1973; 5: 156-160.

9 Biering-Sorensen F, Hansen RB, Biering-Sorensen J. Mobility aids and transport possibilities 10-45 years after spinal cord injury. Spinal Cord 2004; 42 699-706.

10 Howley ET, Bassett DR Jr, Welch HG. Criteria for maximal oxygen uptake: review and commentary. Med Sci Sports Exerc 1995; 27: 1292-1301.

11 Edvardsen E, Hem E, Anderssen SA. End criteria for reaching maximal oxygen uptake must be strict and adjusted to sex and age: a cross-sectional study. PLoS One 2014; 9 : e85276.

12 Fredriksen PM, Ingjer F, Nystad W, Thaulow E. Aerobic endurance testing of children and adolescents-a comparison of two treadmill-protocols. Scand J Med Sci Sports 1998; 8: 203-207.

13 Battikha M, Sa L, Porter A, Taylor JA. Relationship between pulmonary function and exercise capacity in individuals with spinal cord injury. Am J Phys Med Rehabil 2014 93: 413-421.

14 Kirshblum SC, Burns SP, Biering-Sorensen F, Donovan W, Graves DE, Jha A et al. International standards for neurological classification of spinal cord injury (revised 2011). J Spinal Cord Med 2011; 34: 535-546.

15 Bland JM, Altman DG. Statistical methods for assessing agreement between two methods of clinical measurement. Lancet 1986; 1: 307-310.

16 Buchfuhrer MJ, Hansen JE, Robinson TE, Sue DY, Wasserman K, Whipp BJ. Optimizing the exercise protocol for cardiopulmonary assessment. J Appl Physiol 1983; 55: 1558-1564.

17 Miller GS, Dougherty PJ, Green JS, Crouse SF. Comparison of cardiorespiratory responses of moderately trained men and women using two different treadmill protocols. J Strength Cond Res 2007; 21: 1067-1071.

18 Nordrehaug JE, Danielsen R, Stangeland L, Rosland GA, Vik-Mo H. Respiratory gas exchange during treadmill exercise testing: reproducibility and comparison of different exercise protocols. Scand J Clin Lab Invest 1991; 51: 655-658.

19 Lukaski HC, Bolonchuk WW, Klevay LM. Comparison of metabolic responses and oxygen cost during maximal exercise using three treadmill protocols. J Sports Med Phys Fitness 1989; 29: 223-229.

20 Edvardsen E, Scient C, Hansen BH, Holme IM, Dyrstad SM, Anderssen SA. Reference values for cardiorespiratory response and fitness on the treadmill in a 20- to 85-year-old population. Chest 2013; 144: 241-248.

21 Beltrami FG, Wong del P, Noakes TD. High prevalence of false-positive plateau phenomena during V02max testing in adolescents. J Sci Med Sport 2014; 17 526-530.

22 Kang J, Chaloupka EC, Mastrangelo MA, Biren GB, Robertson RJ. Physiological comparisons among three maximal treadmill exercise protocols in trained and untrained individuals. Eur J Appl Physiol 2001; 84: 291-295.

23 Froelicher VF Jr, Brammell H, Davis G, Noguera I, Stewart A, Lancaster MC. A comparison of three maximal treadmill exercise protocols. J Appl Physiol 1974; 36: 720-725. 